\title{
Complex Endometrial Hyperplasia
}

National Cancer Institute

\section{Source}

National Cancer Institute. Complex Endometrial Hyperplasia. NCI Thesaurus. Code C35423.

A hyperplasia characterized by excessive proliferation of endometrial cells, resulting in the formation of complex epithelial structures. Epithelial atypia may be present or absent. 